\title{
Case Report: Viral Shedding for 60 Days in a Woman with COVID-19
}

\author{
Junyao Li, ${ }^{1} \dagger$ Lin Zhang, ${ }^{1} \dagger$ Baihui Liu, ${ }^{2}$ and Debiao Song ${ }^{2 *}$ \\ ${ }^{1}$ Department of Respiratory and Critical Care Medicine, The Second Hospital of Jilin University, Changchun, People's Republic of China; \\ ${ }^{2}$ Department of Emergency and Critical Care Medicine, The Second Hospital of Jilin University, Changchun, People's Republic of China
}

\begin{abstract}
Novel coronavirus disease (COVID-19) caused by severe acute respiratory syndrome-coronavirus-2 (SARS-CoV-2) has become a public health emergency of international concern. This was first noted in Wuhan, Hubei Province, China, and since then has become widespread globally. We report a 71-year-old woman with documented viral shedding (based on reverse transcription-polymerase chain reaction (RT-PCR) testing) of SARS-CoV-2 for 60 days from the onset of symptoms ( 55 days from her first positive test and 36 days after complete resolution of symptoms). This is to our knowledge the longest duration of viral shedding reported to date. This case demonstrates that viral shedding after COVID-19 diagnosis can be prolonged.
\end{abstract}

\section{INTRODUCTION}

In December 2019, an outbreak of severe acute respiratory syndrome-coronavirus-2 (SARS-CoV-2) infection was detected in Wuhan, China. The extensive spread of SARS-CoV-2 has led to a massive pandemic, associated with substantial morbidity and mortality. ${ }^{1}$ Novel coronavirus disease (COVID-19) has spread to more than 200 countries, and the death toll remains very high. ${ }^{2}$ According to some retrospective analyses, the median duration of viral shedding was 12-20 days from illness onset, $^{3-5}$ whereas the longest duration recorded has been 49 days. ${ }^{6}$ We present a case of COVID-19 with viral shedding for 60 days from the onset of symptoms.

\section{CASE PRESENTATION}

On February 10, 2020, a 71-year-old woman who lives in Wuhan was admitted to hospital with a 14-day history of illness, 9 days after a positive reverse transcriptase (RT)-PCR test for SARS-CoV-2 (Figure 1). The patient reported a history of intermittent fever (highest $40.0^{\circ} \mathrm{C}$ ) for the initial 6 days of illness, and dry cough, fatigue, and shortness of breath, which were worse at night for 14 days. She also had nausea, vomiting, and diarrhea for the first 2 days of illness. Because of increasing dyspnea, a computed tomography (CT) scan was conducted on January 30, 2020 (illness day 3); this showed multiple small patchy shadows and interstitial changes, consistent with viral pneumonia. A subsequent oropharyngeal swab RT-PCR test was positive for COVID-19 on February 2, 2020 (illness day 6). The patient was treated as an outpatient with moxifloxacin hydrochloride and Lianhuaqingwen (a Chinese herbal medicine) from days 1 to 13 of illness.

Apart from a history of penicillin allergy, the patient was healthy and a nonsmoker. Despite resolution of fever after day 6 of illness, her symptoms of dry cough and fatigue persisted, and shortness of breath worsened, leading to hospital admission on day 14 of illness. On physical examination, a temperature of $36.6^{\circ} \mathrm{C}$, blood pressure of 139 / $94 \mathrm{mmHg}$, pulse of 84 per minute, respiratory rate of 20 per minute, and oxygen saturation of $94 \%$ breathing room air

*Address correspondence to Debiao Song, Department of Emergency and Critical Care Medicine, The Second Hospital of Jilin University, 218 Ziqiang St., Nanguan District, Changchun 130041, People's Republic of China. E-mail: debiaosong@sina.com

$\dagger$ These authors contributed equally to this work. were recorded. Lung auscultation revealed slightly wet rales from both the lungs, but no dry rales were noted. No obvious abnormalities were found on the rest of the examination.

After admission, the patient received antiviral treatment including peramivir-sodium chloride injection and arbidol tablets according to Chinese Clinical Guidance for COVID-19 Pneumonia Diagnosis and Treatment. ${ }^{7}$ The patient was kept at bed rest with continuous low flow oxygen, with treatment as shown in Figure 2. Laboratory results are shown in Table 1. Computed tomography scan on hospital day 2 (illness day 15) showed multiple patchy shadows, groundglass opacities, and infiltrates in subpleural areas bilaterally (Figure $3 \mathrm{~A}$ and $\mathrm{B}$ ).

From day 4 (illness day 17) of hospitalization, the patient had no fatigue but had occasional dry cough and shortness of breath after activities. On day 5 through 11 of hospitalization (illness days 18-24), her persisting symptoms improved gradually. From hospital day 12 (illness day 25), the patient was asymptomatic, with an oxygen saturation of $97 \%$ on room air, but she remained hospitalized based on local policies. Repeat CT scans showed gradual improvement in lung abnormalities (Figure 3). Repeat SARS-CoV-2 tests of nasopharyngeal and/or oropharyngeal swabs were positive through day 60 of illness, with negative tests on days 64 and 65 (Figure 1). Sinus CT scan on hospital day 41 showed no obvious abnormalities. Given her prolonged viral shedding, the patient received $\mathrm{Y}$-globulin treatment from illness days 56 to 61 . The patient was discharged from the hospital on April 2, 2020, 66 days from the onset of illness, after consecutive nasopharyngeal swabs and an oropharyngeal swab tested negative for SARS-CoV-2. ${ }^{8}$

\section{DISCUSSION}

We report persistent shedding of SARS-CoV-2, based on RT-PCR testing, for 60 days from the onset of typical symptoms of COVID-19 in a 71-year-old Chinese woman. Researchers have reported that both symptomatic and asymptomatic patients can have similar viral loads, suggesting a transmission potential for asymptomatic or minimally symptomatic patients. ${ }^{9,10}$ Our case recovered from a fairly mild episode of COVID-19, with no reported symptoms after illness day 24, but viral shedding persisted for another 36 days. This is to our knowledge the longest duration of SARS-COVID-2 shedding reported to date. 


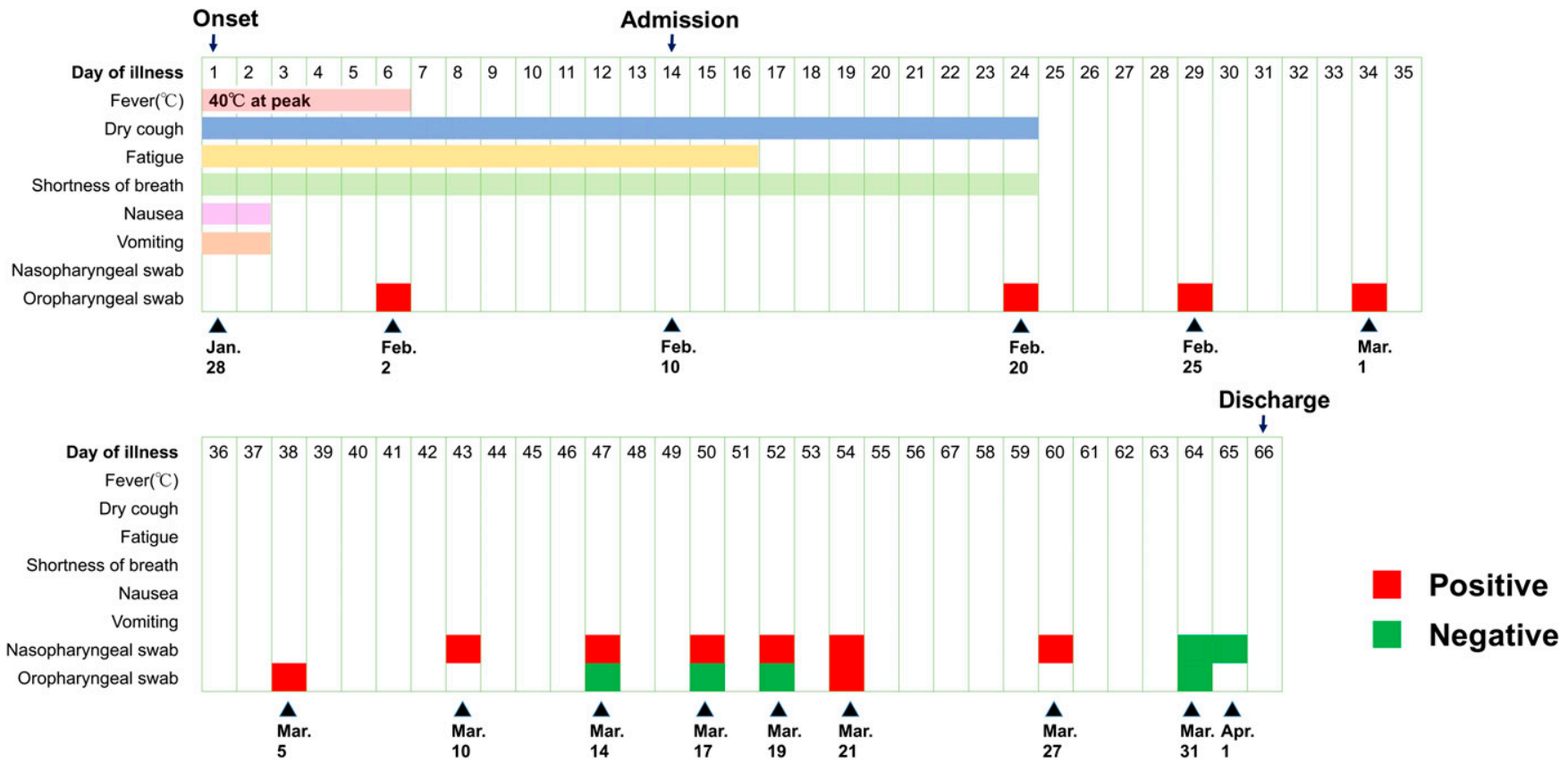

FIGURE 1. Dynamic assessment of symptoms and severe acute respiratory syndrome-coronavirus-2 reverse transcriptase-PCR test results over time.

There have been several reports on infections in close contacts of COVID-19 patients even after apparent clinical recovery of the source patients. ${ }^{11}$ Transmission has also been documented from asymptomatic or minimally symptomatic patients. $^{12,13}$ Similar to previously reported cases, we report prolonged viral shedding after recovery from COVID-19. It remains unclear whether prolonged shedding is associated with prolonged infectivity. Investigation of the importance of the "shedding window" after clinical recovery from COVID-19 is of high priority.

In summary, we reported a case of COVID-19 with viral shedding for 60 days from illness onset and, more importantly, persistent viral shedding 36 days after resolution of symptoms, suggesting that asymptomatic, mildly symptomatic, and recently recovered patients may require prolonged isolation. In addition, further studies based on larger cohorts

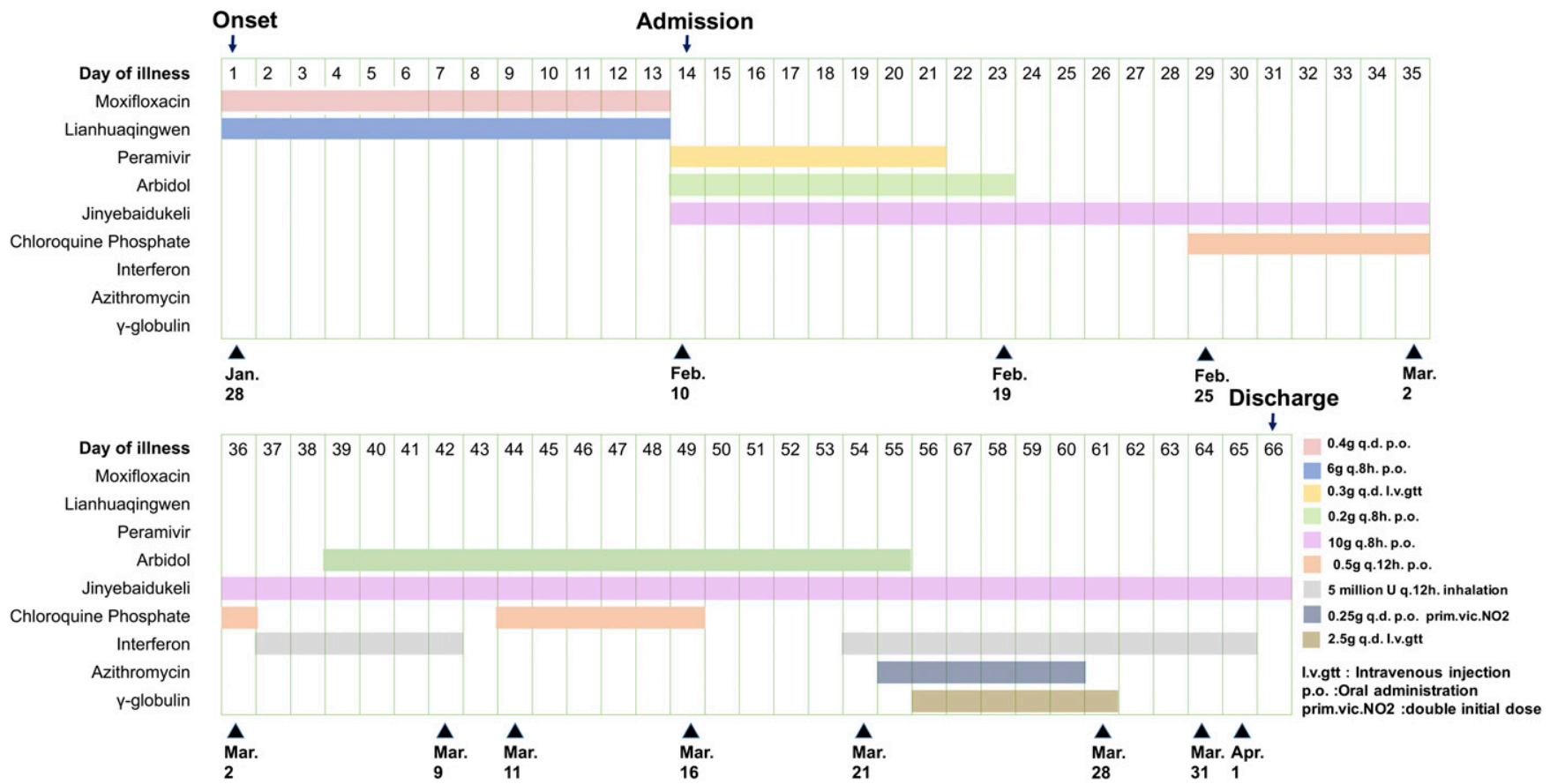

FIGURE 2. Medications administered. 
TABLE 1

Clinical laboratory result

\begin{tabular}{|c|c|c|c|c|c|}
\hline Measure & Reference range & IIIness day 14 & IIIness day 31 & Illness day 45 & IIIness day 61 \\
\hline White cell count $\left(\times 10^{9} / \mathrm{L}\right)$ & $3.50-9.50$ & 4.47 & 3.39 & 3.34 & 4.2 \\
\hline Absolute neutrophil count $\left(\times 10^{9} / \mathrm{L}\right)$ & $1.80-6.30$ & 3.18 & 1.91 & 1.70 & 3.11 \\
\hline Absolute lymphocyte count $\left(\times 10^{9} / \mathrm{L}\right)$ & $1.10-3.20$ & 0.66 & 0.79 & 1.02 & 0.72 \\
\hline Absolute monocyte count $\left(\times 10^{9} / \mathrm{L}\right)$ & $0.10-0.60$ & 0.53 & 0.44 & 0.45 & 0.35 \\
\hline Red cell $\left(\times 10^{9} / \mathrm{L}\right)$ & $3.80-5.10$ & 3.72 & 3.71 & 3.60 & 3.93 \\
\hline Hematocrit (\%) & $35.0-45.0$ & 34.3 & 34.9 & 33.2 & 35.4 \\
\hline Hemoglobin $\left(\times 10^{9} / \mathrm{L}\right)$ & $115.0-150.0$ & 118 & 117 & 112 & 123 \\
\hline Platelet count $\left(\times 10^{9} / \mathrm{L}\right)$ & $125.0-350.0$ & 433 & 218 & 229 & 159 \\
\hline Alanine aminotransferase (U/L) & $\leq 33$ & 18 & 42 & 14 & - \\
\hline Aspartate aminotransferase (U/L) & $\leq 32$ & 19 & 43 & 17 & _ \\
\hline Total protein $(\mathrm{g} / \mathrm{L})$ & $64-83$ & 69.6 & 67.4 & 63.7 & - \\
\hline Albumin $(\mathrm{g} / \mathrm{L})$ & $35-53$ & 32.5 & 37.1 & 36.4 & - \\
\hline Total bilirubin $(\mu \mathrm{mol} / \mathrm{L})$ & $\leq 21$ & 4.3 & 7.7 & 5.2 & - \\
\hline Alkaline phosphatase (U/L) & $35-105$ & 57 & 58 & 53 & - \\
\hline Blood urea nitrogen $(\mathrm{mmol} / \mathrm{L})$ & $3.1-8.8$ & 3.40 & 4.70 & 4.00 & - \\
\hline Creatinine $(\mu \mathrm{mol} / \mathrm{L})$ & $45-84$ & 50 & 64 & 59 & - \\
\hline Lactate dehydrogenase $(\mathrm{U} / \mathrm{L})$ & $135-214$ & 284 & 180 & 220 & 15 \\
\hline Potassium (mmol/L) & $3.50-5.10$ & 3.85 & 4.26 & 4.04 & - \\
\hline Sodium (mmol/L) & $136-145$ & 142.7 & 140.6 & 140.9 & _- \\
\hline Chloride (mmol/L) & $99-110$ & 103.0 & 101.3 & 103.7 & - \\
\hline Calcium (mmol/L) & $2.15-2.57$ & 2.04 & 2.50 & 2.39 & - \\
\hline Glucose (mmol/L) & $4.11-6.05$ & 5.83 & 4.84 & 5.00 & - \\
\hline Procalcitonin $(\mathrm{ng} / \mathrm{mL})$ & $<0.05$ & 0.04 & 0.08 & 0.02 & - \\
\hline Erythrocyte sedimentation rate $(\mathrm{mm} / \mathrm{H})$ & $<20.00$ & 88 & 23 & 16 & 54 \\
\hline C-reactive protein $(\mathrm{mg} / \mathrm{L})$ & $<1$ & 7.6 & 1.7 & 1.6 & - \\
\hline Prothrombin time (seconds) & $11.5-14.5$ & 12.6 & 12.6 & 13.8 & - \\
\hline Fibrinogen $(\mathrm{g} / \mathrm{L})$ & $2.00-4.00$ & 5.88 & 3.47 & 3.22 & - \\
\hline $\mathrm{D}-\operatorname{dimer}(\mu \mathrm{g} / \mathrm{mL})$ & $<0.5$ & 1.99 & 2.08 & 1.53 & - \\
\hline Fer protein ( $\mu \mathrm{g} / \mathrm{L})$ & $15-150$ & - & 228.4 & 165.2 & - \\
\hline Total T lymphocyte $(/ \mu \mathrm{L})$ & $955-2860$ & _ & - & - & 449 \\
\hline T-lymphocyte $\mathrm{CD}^{+} \mathrm{CD} 4+(/ \mu \mathrm{L})$ & $550-1440$ & _- & _ & - & 214 \\
\hline T-lymphocyte $\mathrm{CD}^{+} \mathrm{CD}^{+}(\mathrm{\mu L})$ & $320-1250$ & _ & _ & _ & 180 \\
\hline
\end{tabular}

would help to characterize the duration of viral shedding and infectivity.

Received April 11, 2020. Accepted for publication April 19, 2020.

Published online April 27, 2020.

Acknowledgments: We would like to express our gratitude to all those medical staff's selfless dedication and devotion in this outbreak. We would like to express our gratitude to all the heroic people of Wuhan for their spirit of sacrifice and commitment. We thank the patient who gave us permission for publication. Publication charges for this article were waived due to the ongoing pandemic of COVID-19.

Authors' addresses: Junyao Li and Lin Zhang, Department of Respiratory and Critical Care Medicine, The Second Hospital of Jilin University, Changchun, People's Republic of China, E-mails: lijunyao191@ 126.com and zhanglin@jlu.edu.cn. Baihui Liu and Debiao Song, Department of Emergency and Critical Care Medicine, The Second Hospital of Jilin University, Changchun, People's Republic of China, E-mails: lbh1808865579@sina.com and debiaosong@sina.com.

This is an open-access article distributed under the terms of the Creative Commons Attribution (CC-BY) License, which permits
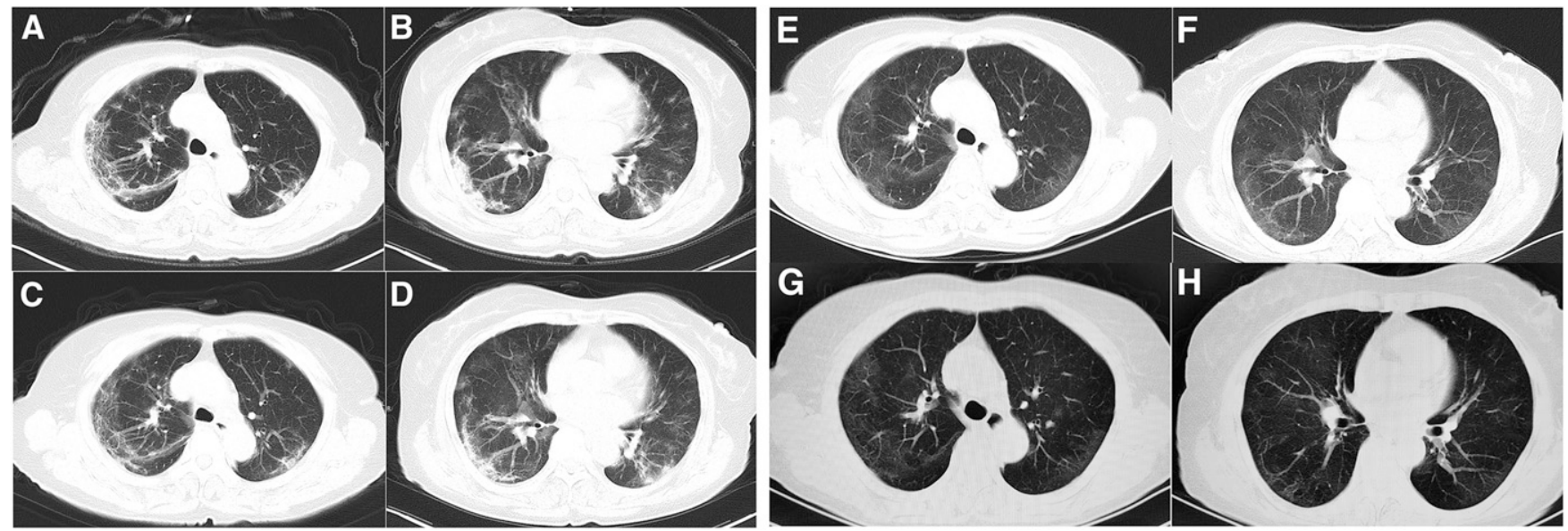

FIGURE 3. Chest computed tomography images. The images show multiple patchy shadows and bilateral subpleural ground-glass opacities and infiltrates, with improvement over time. (A and B): February 11; (C and D): February 17; (E and F): March 6; (G and H): March 21 (illness day 15, 21,39 , and 54, respectively). 
unrestricted use, distribution, and reproduction in any medium, provided the original author and source are credited.

\section{REFERENCES}

1. Phelan AL, Katz R, Gostin LO, 2020. The novel coronavirus originating in Wuhan, China: challenges for global Health Governance. JAMA 323: 709-710.

2. Worldmeters, 2020. Available at: https://www.worldometers.info/ coronavirus/?utm_campaign=homeAdvegas 1 ?. Assessed April 10, 2020.

3. Qian GQ, Chen XQ, Lv DF, Ma AHY, Wang LP, Yang NB, Chen XM, 2020. Duration of SARS-CoV-2 viral shedding during COVID-19 infection. Infect Dis (Lond) 0: 1-2. Available at: https://www. tandfonline.com/doi/abs/10.1080/23744235.2020.1748705.

4. Xu K et al., 2020. Factors associated with prolonged viral RNA shedding in patients with COVID-19. Clin Infect Dis. Available at: https://academic.oup.com/cid/advance-article/doi/10.1093/cid/ ciaa351/5818308

5. Zhou F et al., 2020. Clinical course and risk factors for mortality of adult inpatients with COVID-19 in Wuhan, China: a retrospective cohort study. Lancet 395: 1054-1062.

6. Li T, Kang X, Zhang B, Shangen Z, Bo L, Tiantian Y, Fan Y, Wang Q, Miao H, 2020. A Special Case of COVID-19 with Long Duration of Viral Shedding for 49 Days. Available at: https:// www.medrxiv.org/content/10.1101/2020.03.22.20040071v1. full.pdf+html. Accessed April 19, 2020.

7. General Office of National Health Commission, General Office of National Administration of Traditional Chinese Medicine, 2020.
Diagnostic and treatment - protocol for Novel Coronavirus Pneumonia (Trial version 5, revised form). Available at: http:// www.gov.cn/zhengce/zhengceku/2020-02/09/content_5476407. $\mathrm{htm}$. Accessed February 8, 2020

8. China National Health Commission, 2020. Diagnosis and Treatment of 2019-nCoV Pneumonia in China. In Chinese. Available at: http://www.nhc.gov.cn/yzygj/s7653p/202002/d4b895337e 19445f8d728fcaf1e3e13a.shtml.

9. Zou L et al., 2020. SARS-CoV-2 viral load in upper respiratory specimens of infected patients. N Engl J Med 382: 1177-1179.

10. Rothe $C$ et al., 2020. Transmission of 2019-nCoV infection from an asymptomatic contact in Germany. $N$ Engl $J$ Med 382: 970-971.

11. Lan L, Xu D, Ye G, Xia C, Wang S, LiY1, Xu H, 2020. Positive RT-PCR test results in patients recovered from COVID-19. JAMA 323: 1502-1503.

12. Ye F, Xu S, Rong Z, Xu R, Liu X, Deng P, Liu H, Xu X, 2020. Delivery of infection from asymptomatic carriers of COVID-19 in a familial cluster. Int J Infect Dis. Available at: https://www.sciencedirect. com/science/article/pii/S1201971220301740?via\%3Dihub.

13. Huang L, Zhang X, Zhang X, Wei Z, Zhang L, Xu J, Liang P, Xu PY, Zhang C, Xu PA, 2020. Rapid asymptomatic transmission of COVID-19 during the incubation period demonstrating strong infectivity in a cluster of youngsters aged 16-23 years outside Wuhan and characteristics of young patients with COVID-19: a prospective contact-tracing study. J Infect. Available at: https:// www.sciencedirect.com/science/article/pii/S0163445320301171? via\%3Dihub. 